\title{
LARVICIDAL ACTIVITY OF BACILLUS THURINGIENSIS ISOLATED FROM Bt COTTON RHIZOSPHERE SOIL AGAINST ANOPHELES MOSQUITO LARVAE (CULICIDAE)
}

\author{
JANANI RAJENDRAN, NATHIYA SUBRAMANIAN, RAJESH KANNAN VELU*
}

${ }^{1}$ Rhizosphere Biology Research Group, Department of Microbiology, Bharathidasan University, Tiruchirappalli, Tamil Nadu, India. Email: uvrajesh@gmail.com

Received: 09 June 2018, Revised and Accepted: 01 Aug 2018

\section{ABSTRACT}

Objective: The objective of the study was to isolate and identify Bacillus thuringiensis (Bt) from Bt cotton rhizosphere soil and analyze its larvicidal activity against Anopheles mosquito larvae.

Methods: Soil samples were collected from Bt cotton field, and B. thuringiensis was isolated and characterized by biochemical and microscopical characterization. Crystal (Cry) proteins were extracted and analyzed by sodium dodecyl sulfate-polyacrylamide gel electrophoresis (SDS-PAGE) and its larvicidal activity was checked by mortality analysis. Effective Bt isolates were identified by 16S rRNA sequencing.

Results: A total of 24 isolates were characterized as Bacillus sp. by biochemical characterization. Further, parasporal inclusion and Cry proteins were extracted, and it was quantified by Bradford assay. The precipitated Cry proteins were analyzed by SDS-PAGE and the results have indicates Cry I protein at $100 \mathrm{kDa}$, Cry3 protein at $44 \mathrm{kDa}$, and cytolytic protein (Cyt) at $29 \mathrm{kDa}$ in most of the isolates. Larvicidal activity was checked by the $4^{\text {th }}$ instar Anopheles mosquito larvae. Among the tested isolates, RBL10 and RBL20 have shown the highest percentage of larvicidal activity at 96 and $83 \%$, respectively. Further, the two isolates RBL10 and RBL20 were identified as Bt by $16 \mathrm{~S}$ rRNA sequencing.

Conclusion: B. thuringiensis producing Cry and Cyt proteins posses potential larvicidal activity against Anopheles mosquito larvae which has biological and economic importance in mosquito control.

Keywords: Rhizosphere, Bacillus sp., Cry protein, Larvicidal, Anopheles.

(C) 2018 The Authors. Published by Innovare Academic Sciences Pvt Ltd. This is an open access article under the CC BY license (http://creativecommons. org/licenses/by/4. 0/) DOI: http://dx.doi.org/10.22159/ajpcr.2018.v11i9.27814

\section{INTRODUCTION}

Mosquitoes are the important vectors of several human diseases such as malaria, filariasis, dengue fever, and yellow fever causing serious health problems to world human populations. At present, mosquito-borne diseases are a greater threat in tropical and subtropical countries [1]. The resurgence of these diseases is due to the increase in mosquito breeding places. These disease-causing insects are generally controlled by conventional insecticides [2]. Further, the indiscriminate use of neurotoxic insecticides caused various environmental toxic problems to non-target organisms and insecticidal resistance [3]. Globally, there are conscientious efforts to overcome these problems, and great emphasis is placed recently on eco-friendly and economically viable methodologies for insect control. An alternative approach for mosquito control is the use of natural products such as plant and microorganisms.

Bacillus thuringiensis (Bt) is a soil-dwelling, Gram-positive, rod-shaped, and spore-forming bacterium that produces crystal (Cry) proteins that are toxic to insect species among the orders Lepidoptera, Diptera, and Coleoptera [4-7]. The lethality of Bt to the insects is mainly attributed by the Cry and cytolytic protein (Cyt) proteins, which was produced during the growth cycle $[4,8]$. These Bt strains are found in two different states as either vegetative and can be found as spores. These endospores are resistant to any environmental stress. They are metabolically inactive and a resting form of the bacterium which is a completely different structural form, chemical composition and enzymatic constitution from its vegetative state. The insecticidal activities of the various toxins are differing, but they are considered to be harmless to higher organisms including humans [9]. The Cry proteins are protoxins which can be converted to active toxins on ingestion by a susceptible insect [10]. The microbial insecticides have significant importance in the pest management. Further, when compared with chemical pesticides, these biopesticides are more specific to pests $[11,12]$. The ultimate aim of the present study is to isolate, and screen Cry proteins from Bt from Bt cotton growing rhizosphere soil and an attempt is also made to use of this isolated Cry protein for the control of Anopheles mosquito larvae.

\section{METHODS}

\section{Sample collection}

Soil samples were collected from Bt cotton growing agriculture field at Karai, Perambalur district, Tamil Nadu, India. The samples were collected by scraping off surface material with a sterile spatula, and about $10 \mathrm{~g}$ samples were obtained from 2 to $5 \mathrm{~cm}$ depth. All collected samples were brought to the laboratory in sterile polyethylene bags and stored at $4^{\circ} \mathrm{C}$.

\section{Isolation of Bt}

Isolation of Bt strains was conducted according to the method described by Andrzejczak and Lonc [13]. For Bt isolation M9 medium supplemented with L-serine was used. Approximately, $1 \mathrm{~g}$ of soil sample was suspended in $50 \mathrm{ml}$ test tubes containing $10 \mathrm{ml} 0.9 \% \mathrm{NaCl}$ solution. Suspensions were vortexed vigorously and incubated overnight at $37^{\circ} \mathrm{C}$ until germination was complete. The cells were sedimented by centrifugation and resuspended in $5 \mathrm{ml}$ of $0.9 \% \mathrm{NaCl}$ solution. The suspension was serially diluted and spread on M9 medium, and it was supplemented with $0.2 \mathrm{mM}$ of L-serine. The plates were incubated at $37^{\circ} \mathrm{C}$ for $48 \mathrm{~h}$. Finally, bacterial colonies were separated by their colony morphology. The colonies which showed Bt like colony morphology were rough, white, and spread out over the plate. These colonies were sub-cultured on nutrient agar plates and incubated for $24 \mathrm{~h}$ at $37^{\circ} \mathrm{C}$.

\section{Morphology analysis}

Bt such as colonies, white, large, nearly circular with fine irregular margins and may be glossy, less glossy, or rough was selected. Further, Coomassie 
Brilliant Blue (CBB) staining and phase contrast microscopical analysis were performed for the detection of parasporal crystals in Bt [14]. Apart from that, confocal laser scanning microscopy (CLSM) analysis of Bt cells was also performed. For comparison, the Bt index was calculated for each positive sample as the number of identified Bt colonies divided by the total number of spore-forming Bacilli colonies [15].

\section{Biochemical activity typing}

Biochemical characteristics such as Gram staining, parasporal crystals detection, and phenotypic characterization was accomplished on the basis of biochemical test (Catalase, Oxidase, Citrate, Eosin methylene blue, Methyl red, and Voges-Proskauer), enzyme activity (Amylase test, Protease, and Urease), and hydrolysis test (starch, sucrose, and gelatin) were performed as described by El-Kersh et al. [15].

\section{Antibiotic sensitivity assay}

A total of 24 isolates were tested for antibiotic resistance using the standard agar disc diffusion technique [16] on Mueller-Hinton agar using commercial discs (HiMedia, India). The antimicrobial agents used were ampicillin $(10 \mu \mathrm{g})$, penicillin $\mathrm{G}(10 \mu \mathrm{g})$, vancomycin $(3010 \mu \mathrm{g})$, methicillin $(5 \mu \mathrm{g})$, amikacin $(30 \mu \mathrm{g})$, streptomycin $(10 \mu \mathrm{g})$, and chloramphenicol (30 $\mu \mathrm{g})$. Antimicrobial breakpoints and interpretations were taken from the Clinical and Laboratory Standards Institute (CLSI) standards [17].

\section{In vitro virulence assay}

Virulence properties of the selected isolates were performed by Congo Red dye binding assay (growth on trypticase soy agar supplemented with $0.15 \%$ bile salt and $0.003 \%$ Congo Red) and by testing their hemolysin activity the appearance of red colonies within $72 \mathrm{~h}$ was recorded as a positive reaction and colonies that did not bind the dye and remained white or gray were considered negative [18]. For determination of hemolytic activity, Bt isolates were propagated on blood agar supplemented with 5\% sheep erythrocytes and incubated at $37^{\circ} \mathrm{C}$ for $24 \mathrm{~h}$. Colonies producing clear zones of hemolysis were recorded as hemolysin positive [19].

\section{Precipitation and estimation of proteins}

The highest crystals purity was attained when the hexane was added at a concentration of $10 \%$ which is the closest to the ratio found by Doyle et al. [20] (approximately $133 \mu \mathrm{l}$ hydrocarbon/mL cell suspension) for maximal adherence of spores to hydrocarbons. The purified crystals were air dried (away from light) and weighed. About $10 \mathrm{mg}$ of $99 \%$ pure crystals were obtained from $35 \mathrm{ml}$ of culture. After the alkaline dissolution of the toxin proteins obtained in the culture medium [21], the toxin protein concentration was estimated by the Bradford Method, using the bovine serum albumin as a standard [22]. The crystals recovery yield was calculated according to the following equation: Recovery yield $=$ Crystals dry weight $\times 100 /$ Mass of toxin proteins in the culture.

\section{Cry protein extraction}

The liquid culture medium was centrifuged at $8000 \mathrm{RPM}, 4^{\circ} \mathrm{C}$ for $10 \mathrm{~min}$ and the pellet was obtained. Wash the pellet twice by suspending in $1 \mathrm{M}$ $\mathrm{NaCl}$ containing $0.01 \%$ Triton X-100 by centrifugation at 6000 RPM for $10 \mathrm{~min}$. The pellet was then suspended in a $50 \mathrm{ml}$ centrifuge tube with a $1 \mathrm{ml}$ of saline solution (Change the saline solution volume corresponding to pellet volume). An organic solvent of hexane was added to a ratio $\leq 10 \%(100 \mu \mathrm{l} / \mathrm{ml}$ of aqueous suspension). The suspension was sonicated at $100 \mathrm{~W}$ for $10 \mathrm{~min}$. Centrifuge the sonicated suspension at 6000 RPM for $10 \mathrm{~min}$. The obtained pellet was resuspended in a saline solution, the organic solvent was added again, and the same procedure was repeated 3 times. Finally, the pellet was washed twice with cold distilled water by centrifuge at $6000 \mathrm{RPM}$ for $10 \mathrm{~min}$ [23].

\section{Larvicidal bioassay of Anopheles larvae}

Larvicidal activity of Anopheles by Bt was assessed using the WHO standard method [24]. Four densities were prepared using the McFarland turbidity standard (Standard number 0.5, 1, 2, and 3). In brief, 10 early third instar larvae were added to $100 \mathrm{ml}$ tap water in $200 \mathrm{ml}$ plastic cups in 3 replicates, then $1 \mathrm{ml}$ of spore-Cry mixture of each isolate was added. Similarly, the uninoculated culture medium was used as a control and incubated at room temperature for 12 and $24 \mathrm{~h}$ scoring mortality [25]. All of these three replicates were maintained at the same time. The lethal concentration ${ }_{50}\left(\mathrm{LC}_{50}\right)$ and $\mathrm{LC}_{90}$ value were calculated after $24 \mathrm{~h}$ by probit analysis [26]. A corrected mortality percentage which regarded mortality or dead larvae in the negative control was calculated using Abbott's formula [27-30]. The corrected mortality $=([\%$ mortality in treatment $-\%$ mortality in control $] /[100-$ $\%$ mortality in control] $) \times 100$.

\section{Identification of Bt}

Isolated Bt strains were grown in Luria Britania broth medium at $37^{\circ} \mathrm{C}$ for overnight and genomic DNA was isolated from the culture supernatant by CTAB $\mathrm{NaCl}$ method [31]. For molecular identification 16S rRNA amplification was performed by polymerase chain reaction (PCR). The 16S rRNA was carried out using $0.2 \mu \mathrm{g}$ of DNA template in a reaction mixture with total volume of $50 \mu$ containing each dNTP at a concentration of $400 \mu \mathrm{mol} 1^{-1}$, each primer at a concentration of $1 \mu \mathrm{mol} 1^{-1}$, and each $0.5 \mathrm{U}$ of Taq DNA polymerase (Fermentas, USA) dissolved in the corresponding reaction buffer. PCR amplification of $16 \mathrm{~S}$ rRNA gene from tested $B t$ isolate was performed using the universal primers forward 5'AGAGTTTGATCMTGGCTCAG3' and reverse primer 5'AAGGAGGTGATTCCANCCRCA3'. Amplification was carried out with a thermocycler (Applied Biosystem 2720) under the following conditions $5 \mathrm{~min}$ of initiation at $95^{\circ} \mathrm{C}$, followed by $1 \mathrm{~min}$ of denaturation at $94^{\circ} \mathrm{C}$ by 35 cycles, annealing for $1 \mathrm{~min}$ at $55^{\circ} \mathrm{C}$, and extension for $2 \mathrm{~min}$ at $72^{\circ} \mathrm{C}$. An extra extension step consisting of $10 \mathrm{~min}$ at $72^{\circ} \mathrm{C}$ was added after completion of 35 cycles.

Amplified product was electrophoresed in 1.2\% agarose (Invitrogen) gel electrophoresis, and it was stained with $0.5 \mu \mathrm{g} / \mathrm{ml}^{-1}$ ethidium bromide. Amplified product was purified and sequenced according to Sanger's dideoxynucleotide chain termination method at Bioserve sequence India Pvt. Ltd, Hyderabad. The sequence was obtained, and its similarity was analyzed by nBLAST analysis at https://blast.ncbi.nlm. nih.gov. To determine the genetic relationship phylogenetic tree was constructed by neighbor-joining method using MEGA (version 5.05) software [32].

\section{Sodium dodecyl sulfate-polyacrylamide gel electrophoresis (SDS- PAGE)}

Precipitated protein extract $10 \mu \mathrm{l}$ was mixed with $30 \mu \mathrm{l}$ of concentrated sample loading buffer and the mixture was heated at $80^{\circ} \mathrm{C}$ for $10 \mathrm{~min}$. The processed samples were then loaded on $12 \%$ precast sodium dodecyl sulfate-polyacrylamide gel wells as described by Laemmli [33]. Electrophoresis was carried out at $30 \mathrm{~mA}$ until the tracker dye bromophenol blue reached the bottom of the gel. Gels were stained with a de-staining solution containing $6.75 \%(\mathrm{v} / \mathrm{v})$ glacial acetic acid and $9.45 \%(\mathrm{v} / \mathrm{v})$ methanol. Molecular weights were estimated using SDSPAGE protein molecular weight pre-stained markers (Promega, USA).

\section{Statistical analysis}

For means comparisons to find the significant difference $(p<0.05$ was considered as significant) using Statistical Package for the Social Sciences (SPSS); release 19.0. The $\mathrm{LC}_{50}$ and $\mathrm{LC}_{90}$ (LC required to kill $50 \%$ and $90 \%$ of larvae) were calculated by Probit analysis using SPSS $19.0[26]$.

\section{RESULTS}

Initially, 78 bacterial strains were isolated from the collected soil sample by M9 medium with L-serine supplement. There were 25 putative isolates with typical colony morphology (i.e. Flat, cream, rough surface, and irregular edges) and were determined as Bt. The medium contains many undesirable spore formers, particularly the closely related species of Bt, namely Bacillus anthracis and Bacillus cereus. Motility test was performed, and only the motile isolates were further selected for morphological and biochemical characterization. 
The bacterial isolates are all rod-shaped, Gram-positive, spore formers, after Gram staining the isolates were subjected to CBB staining and CLSM analysis since the technique allowed high-throughput evaluation of the presence of crystals. All 25 isolates were found to be Bt as the presence of parasporal crystals was immediate and striking evidence by the presence of numerous dark blue staining objects in CBB staining (Fig. 1). The use of CBB stains relatively allowed a quick and high throughput assessment of the 25 isolates. Phase contrast microscopy was done after 50 and $90 \mathrm{~h}$ to ensure the presence of rod-shaped vegetative cells and to screen for the presence of parasporal bodies, respectively. The colonies were microscopically examined, and those having visible parasporal inclusions were classified as $\mathrm{Bt}$, and selected for further characterization. In total 8 colonies were identified to be Bt using this method Bernhard et al. [34]. All 25 isolates were shown a positive reaction to catalase test, methyl red test, VP test, Arginine decarboxylation, hydrolysis of starch and gelatin, nitrate reduction and negative reactions to the oxidase test, indole test, tests for citrate

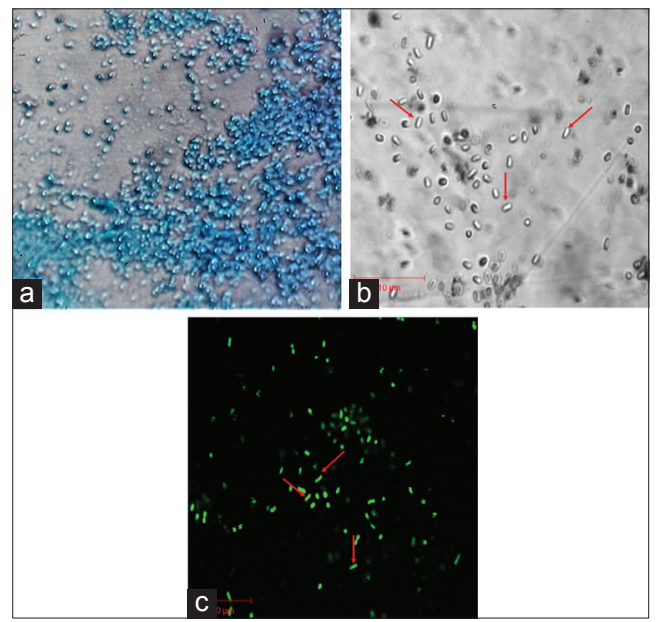

Fig. 1: Microscopical view of Bacillus thuringiensis. (a) Coomassie Brilliant Blue staining, (b) phase contrast microscope, and (c) confocal laser scanning Microscope utilization, and urease test. Isolates were found to ferment glucose and maltose (Table 1).

Mostly Bt is resistant to penicillin, to select the penicillin-resistant Bt, the antibiotic resistance study was conducted with penicillin along with some other related antibiotics. The results were interpreted to the CLSI guidelines (Table 2). All the isolates were shown sensitivity toward the selected antibiotics. In this antibiotic sensitivity test, 96\% of resistance was found to amoxicillin, $84 \%$ of resistance was found to ampicillin, methicillin, and penicillin. The intermediate level of $52 \%$ of resistance was found to vancomycin. Further, $12 \%$ of sensitivity was found to streptomycin, and the least percentage of sensitivity was found to chloramphenicol at 8\% (Fig. 2). In this present study, penicillin resistance has been selected as one of the indicators for selecting the $\mathrm{Bt}$ from others. Except, isolates RBL17, RBL18, RBL21, and RBL22 all the other isolate shows sensitivity toward penicillin.

The isolated bacterial strain virulence was tested by Congo Red binding assay, and $\beta$-hemolytic assay and the Congo Red binding assay have shown $90 \%$ of positive results (Table 2); however, the isolates were protease producers, and it shows $100 \%$ of $\beta$-hemolytic activity. Both these Congo Red binding assays and $\beta$-hemolytic assay results were indicates that the majority of the isolates possess the virulence capacity.

Cry proteins were recovered from the isolated 25 of Bt strains and its average recovery yield were recorded as $53 \%$, and the protein recovery was clearly depicted in Fig. ( 3 and 5). The highest percentage of crystals was observed in the isolate RBL 4, RBL11, and RBL 20 and RBL22 on recovered 99, 91, and 91\%, respectively, remaining other all isolates showed a considerable percentage of protein recovery. The samples having high recovery yield were quantified by Bradford assay and the results indicates that the protein present in all the samples ranges from 9 to $23 \mathrm{mg} / \mathrm{ml}$ (Fig. 4). Further, with this recovered protein, larvicidal activity was checked in Anopheles mosquito larvae, and the results were indicate that among the 24 isolates 10 isolates showed larvicidal activity against the Anopheles mosquito larvae. Among the 10 isolates, RBL10 and RBL20 have shown the highest percentage of mortality toward the $4^{\text {th }}$ instars Anopheles mosquito larvae which were recorded as 96 and 83\%, respectively. The obtained results were

Table 1: Biochemical characterization

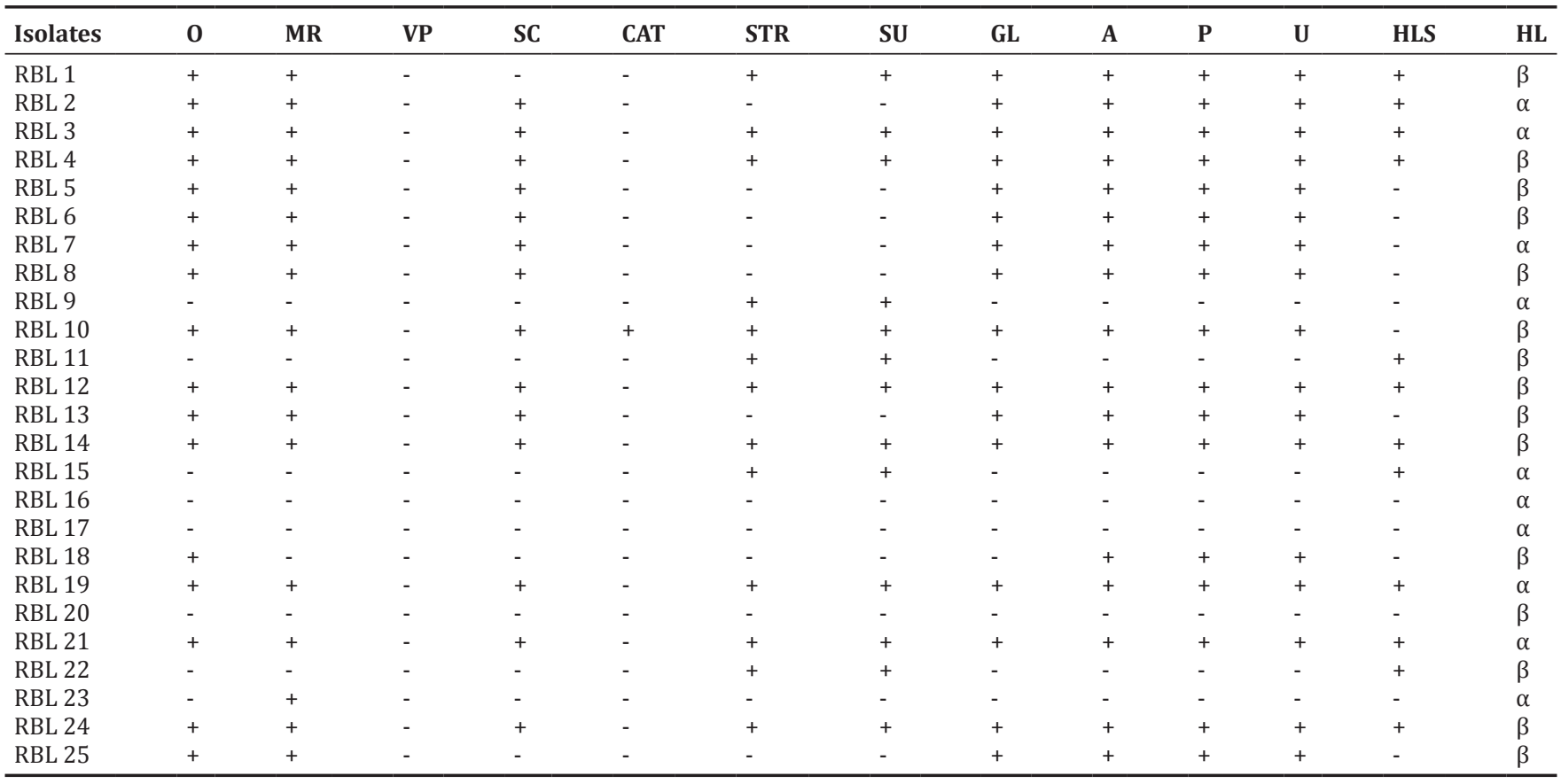

O: Oxidase, MR: Methyl red, VP: Voges proskaur, SCA: Simmon citrate agar, CAT: Catalase, STR: Starch hydrolysis, SU: Sucrose hydrolysis, GL: Gelatin hydrolysis,

A: Arginine decarboxylation, PT: Protease; UR: Urease, HLS: Hydrolysis of starch, HL: Hemolysis 
statistically analyzed through probit analysis and its inferior limit, and the upper limit was calculated. Further, $\mathrm{LC}_{50}$ and $\mathrm{LC}_{90}$ were calculate for the larvicidal activity (Table 2). The isolates RBL10 and RBL20 have the very lowest $\mathrm{LC}_{50}$ value when compare with the other isolates which were recorded as 0.082 and $0.115 \mathrm{mg} / \mathrm{ml}$. However, the other isolate
RBL $9,11,12,15$, and 20 showed $\mathrm{LC}_{50}$ of $0.216,0.386,0.179,0.751$, and $0.784 \mathrm{mg} / \mathrm{ml}$, respectively.

Based on the above biochemical characteristics 2 numbers of Bt were selected for the 16S rRNA analysis. The genomic DNA of the selected

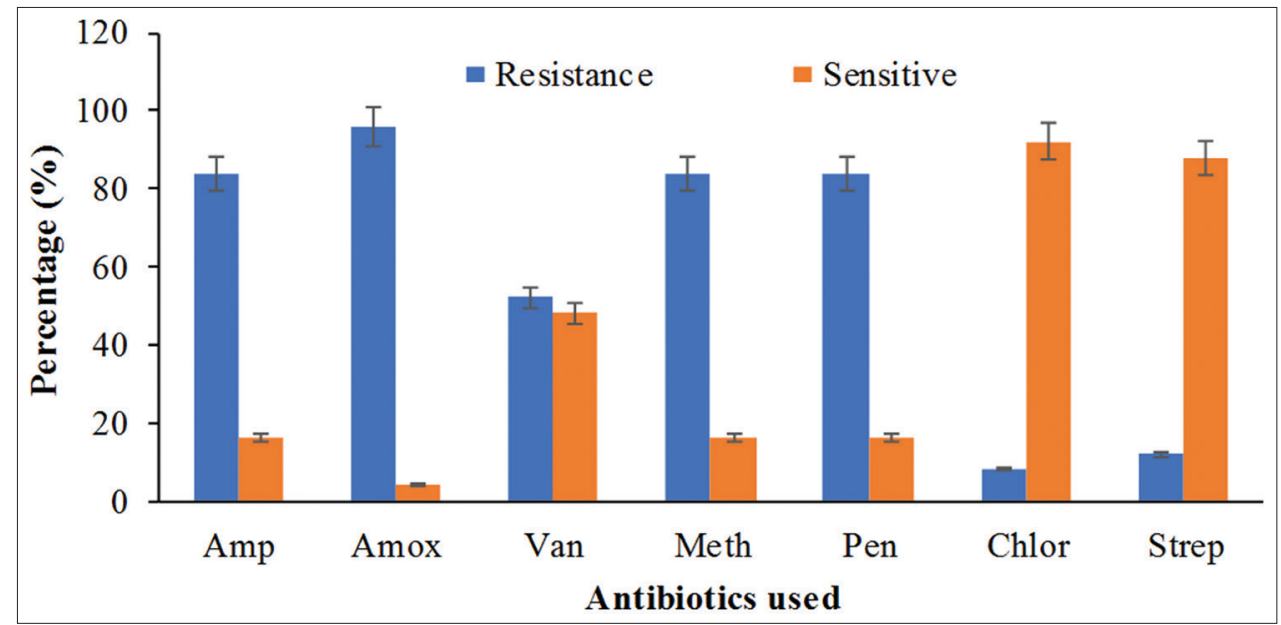

Fig. 2: Antibiotic sensitivity test. Amp: Ampicillin, Amox: Amoxicillin, Van: Vancomycin, Met: Methicillin, Pen: Penicillin, Chlor: Chloramphenicol, Strep: Streptomycin

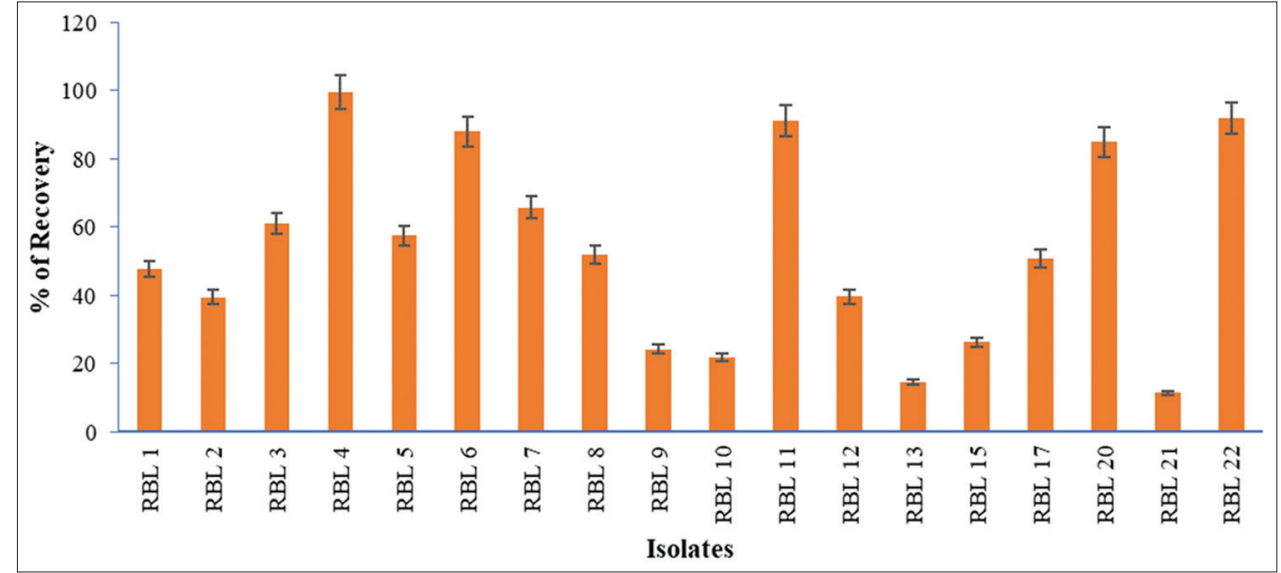

Fig. 3: Recovery of crystal protein. Bars represent means of \pm standards of duplicates

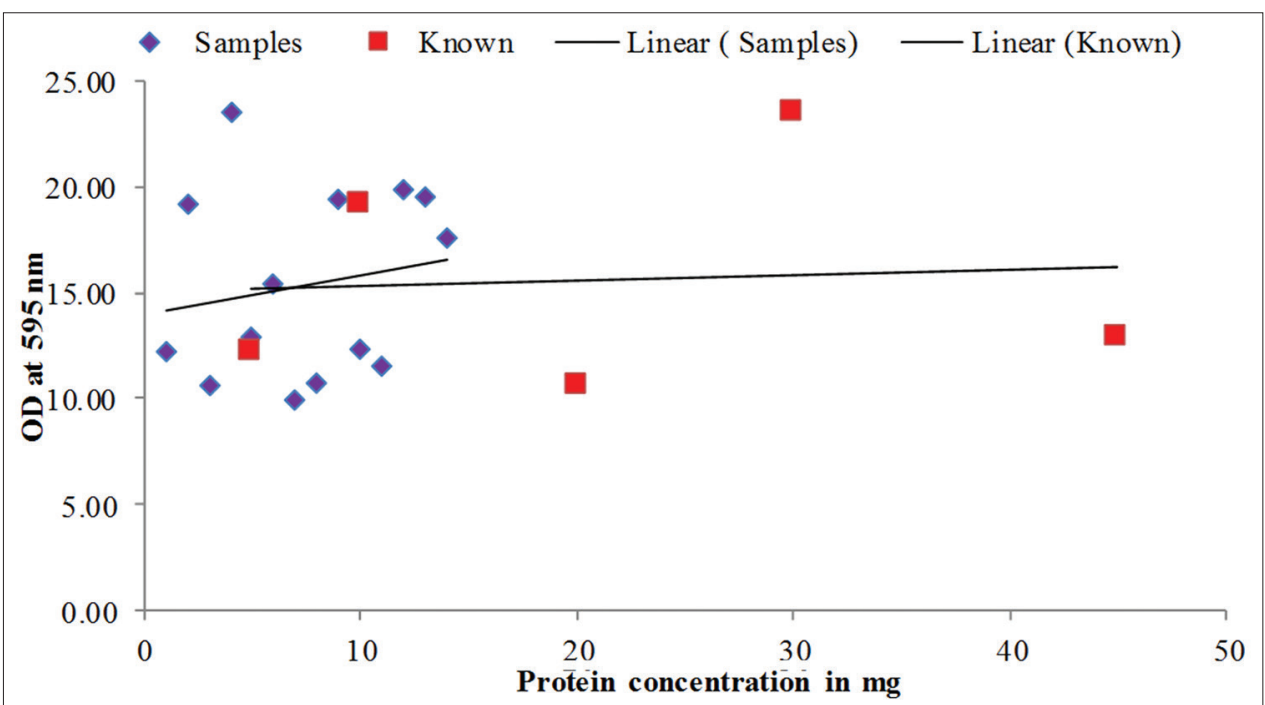

Fig. 4: Protein estimation by Bradford assay 
Bt was isolated, and it was separated by agarose gel electrophoresis. A clear band was observed under the gel doc imaging system. 16S rRNA was amplified by the PCR technique using universal $16 \mathrm{~S}$ rRNA primers (27F and $1522 \mathrm{R}$ ). The PCR product was analyzed in $1 \%$ agarose gel, and amplified product was observed at $900 \mathrm{bp}$ as a clear, sharp band (Fig. 5).

The amplified product was sequenced, and sequence similarity was checked using BLAST analysis, the result has shown that the isolate genomes were highly homologous to the Bt genome $(99 \%$ in homologous). The $16 \mathrm{~S}$ rDNA sequence was deposited in the NCBI Gene Bankit nucleotide sequence database under accession number KU513832 (RBL10) and KU513833 (RBL20). Further, a phylogenetic tree was constructed by a neighbor-joining method using MEGA 5.0 software, and the isolates are closely related to Bt (Fig. 6).

Table 2: Larvicidal bioassay

\begin{tabular}{lllll}
\hline Sample & LC $_{\mathbf{5 0}}$ & LC $_{\mathbf{9 0}}$ & \multicolumn{1}{l}{ CI } & \\
\cline { 4 - 5 } & & & IL & UL \\
\hline RBL 6 & 4.404 & 2.717 & 0.208 & 1.729 \\
RBL 7 & 1.126 & 1.963 & 2.003 & 8.610 \\
RBL 9 & 0.216 & 1.990 & 0.653 & 2.005 \\
RBL10 & 0.082 & 0.164 & 0.087 & 8.606 \\
RBL 11 & 0.386 & 3.268 & 0.713 & 2.052 \\
RBL 12 & 0.179 & 1.125 & 0.897 & 2.315 \\
RBL 13 & 2.543 & 4.693 & 1.805 & 7.820 \\
RBL 15 & 0.751 & 1.364 & 1.903 & 7.999 \\
RBL 20 & 0.115 & 0.575 & 1.032 & 2.639 \\
RBL 21 & 0.784 & 9.980 & 0.449 & 1.821
\end{tabular}

CI: Confidence interval, estimated at $95 \%$ probability through Probit's Analysis,

IL: Inferior limit; UL: Upper limit; LC: Lethal concentration

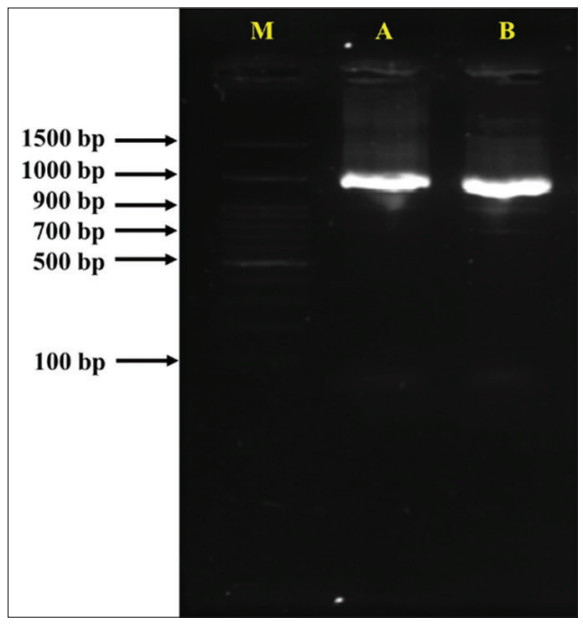

Fig. 5: Agarose gel electrophoresis of $16 \mathrm{~S}$ rRNA M- $100 \mathrm{bp}$ Molecular marker: A - RBL10, B-RBL20
Further, Cry protein profiles of Bt RBL10 and RBL20 were analyzed by discontinuous SDS-PAGE which was revealed that the protein bands with a molecular weight range from $29 \mathrm{kDa}$ to $100 \mathrm{kDa}$ (Fig. 7). The tabulated results have shown that the prominent polypeptide band at a molecular weight of approximately $100 \mathrm{kDa}$ (Cry 1 ) was present in $\mathrm{Bt}$ (RBL10). A 29kDa (Cyt 2) band and 44kDa (Cry 3) band were observed in both Bt RBL10 and RBL20.

\section{DISCUSSION}

Present scenario controlling of mosquito is one of the most important public health practices in tropical countries. Because, most of the diseases are spread through mosquitoes, and many mosquito control strategies like chemical pesticides are followed, and it leads to an increase in mosquito resistance and environmental pollution. Hence, these methods are not encouraged to follow further and to replace this; an eco-friendly method has been promoted to control the mosquitoes.

The present study was described the larvicidal activity of $B t$ from Bt cotton grown soil. Similarly, the isolation and identification of Bt from soil sample were performed by several researchers $[14,35,36]$. Microscopical methods were provided the better isolation of $B t$ among the others based on their morphology and its parasporal crystals [37]. These parasporal crystals composed of Cry and Cyt proteins. Apart from the morphological features, biochemical characterization provides the clear identification of Bacillus sp. which helps to identify Bt from other closely related genus [14].

The Cry and Cyt proteins are present in the binary form, and it took a major role in insect control which it was produced at the time of vegetative stages of Bacillus [38,39]. Many researchers have reported that this binary toxin targets midgut of the larvae at the time of ingestion and/ or after ingestion by the susceptible larvae, crystals are is solubilized at the larval midgut and the release of two proteins which it was cleaved by an endogenous protease to active toxin $[5,10]$. There was no report of resistance development among the mosquito vectors against $\mathrm{Bt}$, unlike the Bacillus sphaericus to which development of resistance was already reported [40]. The present study, larvicidal activity was conducted in laboratory condition on Anopheles mosquito with $24 \mathrm{~h}$ and resulted in the good larvicidal activity. Likewise, Aissaoui and Boudjelida [40] reported, the same effects were found when the B. sphaericus was used against Anopheles stephensi. The target mosquitos were sensitive to the Cry and Cyt proteins and exceptionally some larvae survived in the short term which also died after attaining the next larval stages. This may be due to the influences, including, genetics, amount of toxin ingested, degree of larval midgut damage and finally the mode of action of the toxin. The previous study reported that some of the components of binary toxins synergically bind to specific receptors in larval midgut and cause a formation of pores in the epithelial cell membrane which induce the death of larvae [41].

\section{CONCLUSION}

The present study demonstrated that rhizosphere soil having the wide range of Bacillus sp. population in Bt cotton growing soil with a lot of potentials. Particularly, all of the Bacillus sp. produce Cry proteins. Among them, Bt strains RBL10 and RBL20 produced Cry and Cyt

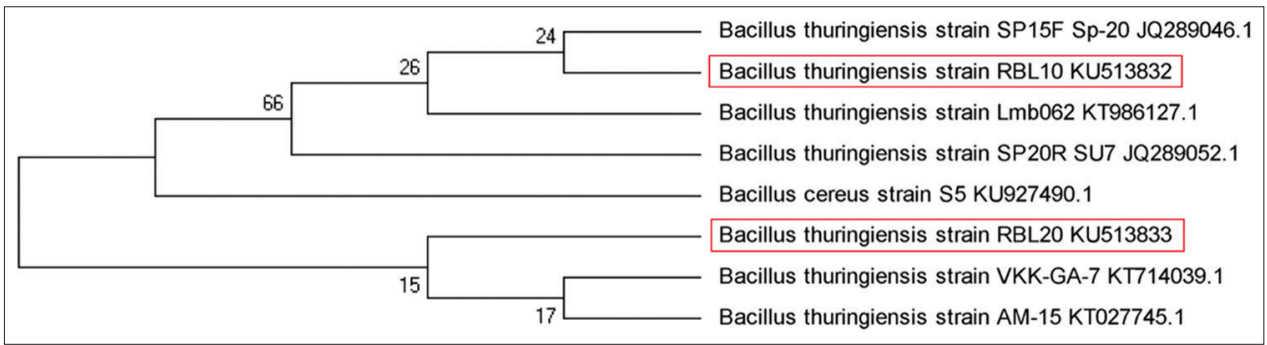

Fig 6. Phylogenetic tree; the evolutionary relationship was inferred using the Maximum Likelihood method based on the Kimura 2-parameter model. The tree is drawn to scale, with branch lengths measured in the number of substitutions per site 


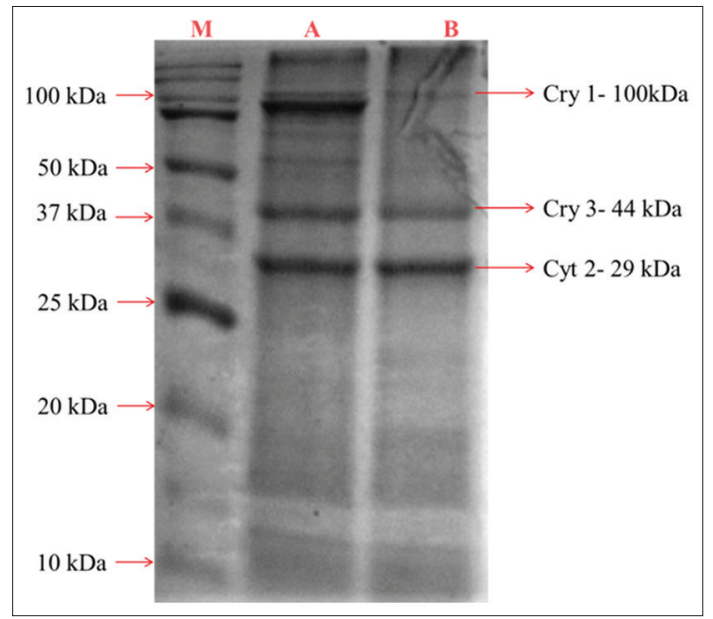

Fig. 7: Sodium dodecyl sulfate-polyacrylamide gel electrophoresis analysis of crystal proteins. M- Molecular weight marker; 1-RBL10, 2 - RBL20

related protein, which possess larvicidal activity against the Anopheles mosquito larvae. The current study results reveal that these two isolates RBL10 and RBL20 having biological and economic importance in the control of mosquito larvae.

\section{ACKNOWLEDGMENT}

The author Janani Rajendran is thankful to the Bharathidasan University, Tamil Nadu, India, for their financial support in the form of University Research Fellow to carry out this research work. The authors also thank DST-PURSE for a confocal microscope facility at Bharathidasan University, Tiruchirappalli, Tamil Nadu, India.

\section{AUTHOR'S CONTRIBUTION}

Janani Rajendran conceived the presented idea, further designed and performed the experiments also wrote the manuscript. Author Nathiya Subramanian helped to carry out the experiments. Rajesh Kannan supervised and provided critical feedback, helped to shape the research, analysis, and manuscript.

\section{CONFLICTS OF INTEREST}

The authors declare that they have no conflicts of interest.

\section{REFERENCES}

1. Rajesh K, Dhanasekaran D, Tyagi BK. Mosquito survey and larvicidal activity of actinobacterial isolates against Culex larvae (Diptera: Culicidae). J Saudi Soc Agric Sci 2015;14:116-22.

2. Cuervo-Parra JA, Cortés TR, Ramirez-Lepe M. Mosquito-Borne diseases, pesticides used for mosquito control, and development of resistance to insecticides. In: Trdan S, editor. Insecticides Resistance. New York: In Tech Open; 2016. p.112-134.

3. Gill HK, Garg H. Pesticides: Environmental impacts and management strategies. In: Soloneski S, editor. Pesticides-Toxic Aspects. New York: In Tech Open; 2014. p. 187-230.

4. Höfte H, Whiteley HR. Insecticidal crystal proteins of Bacillus thuringiensis. Microbiol Rev 1989;53:242-55.

5. Bravo A, Gill SS, Soberón M. Mode of action of Bacillus thuringiensis Cry and Cyt toxins and their potential for insect control. Toxicol 2007;49:423-35.

6. Pardo-Lopez L, Soberon M, Bravo A. Bacillus thuringiensis insecticidal three-domain Cry toxins: Mode of action, insect resistance and consequences for crop protection. FEMS Micro Bio Rev 2012;37:3-22.

7. Soberón M, López-Díaz JA, Bravo A. Cyt toxins produced by Bacillus thuringiensis: A protein fold conserved in several pathogenic microorganisms. Peptides 2013;41:87-93.

8. Aronson AI, Beckman W, Dunn P. Bacillus thuringiensis and related insect pathogens. Microbiol Rev 1986;50:1
9. Vega FE, Kaya HK. Insect Pathology. San Diego: Academic Press; 2012.

10. Feitelson JS, Payne J, Kim L. Bacillus thuringiensis: Insects and beyond. Nat Biotechnol 1992;10:271-5.

11. Popp J, Pető K, Nagy J. Pesticide productivity and food security. A review. Agro Sust Develop 2013;33:243-55.

12. Ravensberg WJ. Commercialization of microbes: Present situation and future prospects. In: Principles of Plant-Microbe Interactions. Berlin: Springer; 2015. p. 309-17.

13. Andrzejczak S, Lonc E. Selective isolation of Bacillus thuringiensis from soil by use of L-serine as minimal medium supplement. Polish J Microbiol 2008;57:333-5.

14. Fakruddin M, Hossain Z, Afroz H. Prospects and applications of nanobiotechnology: A medical perspective. J Nanobiotechnol 2012;10:31

15. El-Kersh TA, Ahmed AM, Al-Sheikh YA, Tripet F, Ibrahim MS, Metwalli AA. Isolation and characterization of native Bacillus thuringiensis strains from Saudi Arabia with enhanced larvicidal toxicity against the mosquito vector Anopheles gambiae. Paras Vector 2016;9:647.

16. Bauer AW, Kirby WM, Sherris JC, Turck M. Antibiotic susceptibility testing by a standardized single disk method. Am J Clin Pathol 1966;45:493.

17. Clinical and Laboratory Standards Institute. Performance Standards for Antimicrobial Susceptibility Testing. Vol. 17. Wayne, PA. Clinical and Laboratory Standards Institute; 2007.

18. Sharada R, Ruban SW. Isolation, characterization and antibiotic resistance pattern of Escherichia coli isolated from poultry. Am Eur J Sci Res 2010;5:18-22.

19. Bodade RG, Khobragade CN, Borkar PS, Manwatkar RN. Haemolytic activity of some pathogenic bacteria in mammals. J Cell Tis Res 2009;9:1865.

20. Doyle RJ, Nedjat-Haiem F, Singh JS. Hydrophobic characteristics of Bacillus spores. Curr Microbiol 1984;10:329-32.

21. Rivera D. Growth kinetics of Bacillus thuringiensis. Doctoral Dissertation, Doctoral Dissertation. London: The University of Western Ontario; 1999.

22. Bradford MM. A rapid and sensitive method for the quantitation of microgram quantities of protein utilizing the principle of protein-dye binding. Anal Biochem 1976;72:248-54.

23. Mounsef JR, Salameh D, Kallassy-Awad M, Chamy L, Brandam C, Lteif RA. Simple method for the separation of Bacillus thuringiensis spores and crystals. J Microbiol Met 2014;107:147-9.

24. World Health Organization. Report of the WHO Informal Consultation on the Evaluation and Testing of Insecticides. Geneva: World Health Organization; 1996.

25. Aramideh S, Saferalizadeh MH, Pourmirza AA, Bari MR, Keshavarzi M, Mohseniazar M. Characterization and pathogenic evaluation of Bacillus thuringiensis isolates from West Azerbaijan province-Iran. Afr J Microbiol Res 2010;4:1224-9.

26. Finney DJ, Tattersfield F. Probit Analysis. Cambridge: Cambridge University Press; 1952

27. Vidal-Quist JC, Castañera P, González-Cabrera J. Cyt1 Aa protein from Bacillus thuringiensis (Berliner) Serovar israelensis is active against the Mediterranean fruit fly, Ceratitis capitata (Wiedemann). Pes Manage Sci 2010;66:949-55.

28. Abbott WS. A method of computing the effectiveness of an insecticide. J Econ Entomol 1925;18:265-7.

29. El Akhal FO, Guemmouh RA, Maniar S, Taghzouti K, El Ouali LA. Larvicidal activity of essential oils of Thymus vulgaris and Origanum majorana (Lamiaceae) against of the malaria vector Anopheles labranchiae (Diptera: Culicidae). Int J Pharm Pharm Sci 2016;853:372-6.

30. Ashwini U, Taju G, Thirunavukkarasu P, Asha S. Pupal emergence inhibition activity of Acalypha indica leaf extract against dengue vector, Aedes albopictus mosquito. Int J Pharm Pharm Sci 2017;9:114-8.

31. Möller EM, Bahnweg G, Sandermann H, Geiger HH. A simple and efficient protocol for isolation of high molecular weight DNA from filamentous fungi, fruit bodies, and infected plant tissues. Nucl Aci Res 1992;20:6115.

32. Tamura K, Stecher G, Peterson D, Filipski A, Kumar S. MEGA6: Molecular evolutionary genetics analysis version 6.0. Mole Biol Evol 2013;30:2725-9.

33. Laemmli UK. Cleavage of structural proteins during the assembly of the head of bacteriophage T4. Nature 1970;227:680-5.

34. Bernhard K, Jarrett P, Meadows M, Butt J, Ellis DJ, Roberts GM, et al. Natural isolates of Bacillus thuringiensis: Worldwide distribution, 
characterization, and activity against insect pests. J Invert Pathol 1997;70:59-68.

35. Balaraman K. Mosquito control potential of Bacillus thuringiensis subsp. israelensis and Bacillus sphaericus. ICMR Bull 1995;25:45-51.

36. Prabakaran G, Balaraman K. Development of a cost-effective medium for the large scale production of Bacillus thuringiensis var israelensis. Biol Cont 2006;36:288-92.

37. Rampersad J, Khan A, Ammons D. Usefulness of staining parasporal bodies when screening for Bacillus thuringiensis. J Invert Pathol 2002;79:203-4.

38. Federici BA, Lüthy P, Ibarra JE. Parasporal body of Bacillus thuringiensis israelensis. Bacterial Control of Mosquitoes and Black
Flies. New Brunswick: Springer; 1990. p. 16-44.

39. Ibarra JE, Federici BA. Isolation of a relatively nontoxic 65-kilodalton protein inclusion from the parasporal body of Bacillus thuringiensis subsp. israelensis. J Bacteriol 1986;165:527-33.

40. Aissaoui A, Boudjelida H. Larvicidal activity and influence of Bacillus thuringiensis (Vectobac G), on longevity and fecundity of mosquito species. Eur J Exp Biol 2014;4:104-9.

41. Schwartz JL, Potvin L, Coux F, Charles JF, Berry C, Humphreys MJ, et al. Permeabilization of model lipid membranes by Bacillus sphaericus mosquitocidal binary toxin and its individual components. J Mem Biol 2001;184:171-83. 